\title{
ANALYSIS OF OFF-SEASON CUCUMBER PRODUCTION EFFICIENCY IN PUNJAB: A DEA APPROACH
}

\section{Qamar Ali ${ }^{1,2, *}$, Muhammad Ashfaq ${ }^{3}$ and Muhammad Tariq Iqbal Khan ${ }^{4}$}

\author{
Institute of Agricultural and Resource Economics, University of Agriculture, Faisalabad \\ ${ }^{2}$ Instructor, Department of Economics, Virtual University of Pakistan, Faisalabad Campus \\ ${ }^{3}$ Professor and Doctor, Institute of Agricultural and Resource Economics, University of Agriculture, Faisalabad \\ ${ }^{4}$ Lecturer, Department of Economics, Government Postgraduate College, Jaranwala
}

Received - September 12, 2016; Revision - October 25, 2016; Accepted - November 06, 2016

Available Online - November 13, 2016

DOI: http://dx.doi.org/10.18006/2016.4(Issue6).653.661

\section{KEYWORDS}

Off-season cucumber

Technical

Allocative

Economic

Efficiency

DEA Approach

Tobit Model

\begin{abstract}
The current research was designed to estimate technical, allocative and economic efficiency and determinants of inefficiency in the cultivation of off-season cucumber in Punjab, Pakistan. Simple random sampling was selected for the collection of primary data from 70 off-season cucumber growers in 2014. Data Envelopment Analysis Procedure revealed that average value of technical efficiency was higher $(87.4 \%)$ followed by allocative $(42.0 \%)$ and economic efficiency $(37.2 \%)$. It shows the potential of $12.6 \%$ reduction in the level of input use and $58.0 \%$ reduction in total cost for obtaining same output level with same technology. The lowest value of technical (60.7\%), allocative (13.7\%) and economic (9.9\%) efficiency was also calculated. Medium farmer shows high value of technical $(96.7 \%)$ and economic $(46.5 \%)$ efficiency while allocative $(49.0 \%)$ efficiency was higher in case of small farmer. Inefficiency determinants shows that the education, experience in off-season cucumber production and number of meetings with extension staff had significant and negative effect on inefficiency score. The effect of family size, off-season cucumber area and distance of vegetable market from vegetable farm was significant and positive on inefficiency score. Government should take steps for the improvement in education, technical knowledge, meetings with extension staff and quality of inputs. Government should provide subsidy to small farmers in the purchase of tunnel material.
\end{abstract}

* Corresponding author

E-mail: qamarali2402@gmail.com (Qamar Ali)

Peer review under responsibility of Journal of Experimental Biology and Agricultural Sciences.

Production and Hosting by Horizon Publisher India [HPI] (http://www.horizonpublisherindia.in/).

All rights reserved.
All the article published by Journal of Experimental Biology and Agricultural Sciences is licensed under a Creative Commons Attribution-NonCommercial 4.0 International License Based on a work at www.jebas.org.

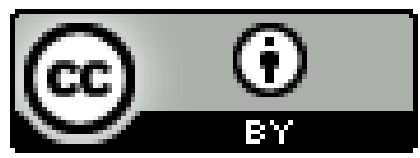




\section{Introduction}

Government promoted new technologies for the improvement in agriculture sector. The share of agriculture sector was $19.8 \%$ in gross domestic product with the involvement of $42.3 \%$ labor force (Government of Pakistan, 2016a). There is a strong association exists between agriculture and various climate factors like precipitation, temperature, floods which ultimately influence on the economy of a country. Increase in the production as well as yield of agricultural crops is a need of time for successful achievement of food security (Government of Pakistan, 2015; Government of Pakistan, 2016a).

Vegetables are considered as an essential part of agriculture because these are a source of livelihood and foreign exchange. These are useful for health, maintenance of nutrition level and resistance against diseases (Ogunniyi \& Oladejo, 2011; Ibrahim \& Omotesho, 2013). There exists $120 \%$ expansion in the production of vegetables on the globe (Bozoglu \& Ceyhan, 2007). Major problems faced by developing countries were unemployment, poverty and malnutrition. The sector of vegetables can tackle these problems in short period of time. Their short growing period was also helpful in the cultivation of many crops in a particular season (Akter et al., 2011).

The value of vegetables and fruits export was 47895.6 million rupees in 2010-11 but the amount becomes 66531.3 million rupees in 2015-16 (Government of Pakistan, 2016b). Per capita recommended use of vegetables was $73 \mathrm{~kg}$ on annual basis but per capita annual vegetable consumption was $27.4 \mathrm{~kg}$ less in Pakistan (Shaheen et al., 2011).

Cucumber (Cucumis sativus L.) is a popular vegetable of Cucurbitaceae family having 118 genera and 825 species (Khan et al., 2015; Maurya et al., 2015). It is growing in western Asia since last 3,000 years but India is marked as their homeland (Maurya et al., 2015). Its local name is Khira and is an essential ingredient of salad. It is real versatile vegetable because of variety in their use from salad to pickles as well as from digestive aids to beauty products. It was found useful against human constipation and improvement in digestion (Maurya et al., 2015). It is used as a cooling food in summer (Maurya et al., 2015). A fresh cucumber provides vitamin C, niacin, iron, calcium, thiamine, fibers and phosphorus (Khan et al., 2015; Sanjeev et al., 2015). More than 50\% production of cucumber comes from Asia. Turkey, Iran, Uzbekistan, Japan and Iraq were considered as leading cucumber producing countries in Asia (Khan et al., 2015).

In Pakistan, the cultivation area under cucumber and gherkins was 3,528 ha in 2013 while it was 3,499 ha in 2012. Total production of cucumber and gherkins was 50,164 tonnes in 2013 while it was 49,947 tonnes in 2012 (FAO, 2016). Yield of cucumber and gherkins was $14,218.8 \mathrm{~kg} \mathrm{ha}^{-1}$ in 2013 while it was $14,274.6 \mathrm{~kg} \mathrm{ha}^{-1}$ in 2012. So, the area and total production showed $0.83 \%$ and $0.43 \%$ increase, respectively.
However, there is $0.39 \%$ decrease in per hectare yield (FAO, 2016).

In Punjab, the cultivation area under cucumber was 1,795 hectares in 2012-13 while it was 1,742 hectares in 2011-12. Total production of cucumber was 40,439 tonnes in 2012-13 while it was 38,952 tonnes in 2011-12. Punjab contributes $80.96 \%$ in the total production of cucumber in 2012-13 while its area under cucumber cultivation was $51.30 \%$ of total area under cucumber cultivation in Pakistan in 2012-13. It shows that the average yield was higher in Punjab as compared to other provinces (Government of Pakistan, 2014).

Off-season vegetable production was useful for the reduction in high prices at start and end of vegetable season. Temperature and moisture level were under the control of farmers in off-season or tunnel farming (Government of Pakistan, 2013). Extension in the season and yield of a particular vegetable is observed in case of off-season cultivation (Iqbal et al., 2009).

The yield difference was observed in case of different farmers due to difference in the use of inputs. It indicates the existence of inefficiency in input usage (Khan \& Ghafar, 2013). Production function, mathematical programming and frontier function techniques were used for the measurement of technical efficiency of agricultural farms (Bozoglu \& Ceyhan, 2007). Therefore, it is required to uplift the living standard of vegetable farmers by improving their technical efficiency (Ibrahim \& Omotesho, 2013).

Alboghdady \& Shata (2014) explored the technical efficiency in the production of cucumber under greenhouses, plastic tunnels and open field system. Results confirmed the difference in efficiency among various cultivation systems. They pointed out toward the improvement of efficiency and productivity. Education, extension services and agricultural knowledge were found beneficial for the improvement of efficiency.

Similarly, Shrestha et al. (2014) demonstrated the efficiency in the production of vegetables in Nepal. Average technical efficiency was 0.77 and pointed out $23 \%$ expansion in the production of vegetables. They recommended improvement in land, seed quality, pesticide and fertilizer availability, labour skills, women participation, extensions services and credit availability.

The current research was designed for the estimation of production efficiency in off-season cucumber production and checked the opportunity of input reduction keeping output level as constant or opportunity of obtaining more output keeping the input use level constant. The study also designed to give policy implications in the light of results. The production efficiency of off-season cucumber production was further decomposed into technical, allocative and economic 
efficiency with the help of Data Envelopment Analysis

Procedure.

\section{Material and Methods}

\subsection{Data and study area}

The present study used a comprehensive questionnaire for primary data collection from off-season cucumber growers in Toba Tek Singh and Faisalabad districts of Punjab, Pakistan in 2014. Simple random technique was adapted to interview offseason cucumber growers about socio-economic variables like education, size of family, off-season cucumber growing experience, contacts with extension agents, distance of vegetable market. They were also asked about the prices and quantity of inputs and output. A sample size of 60 respondents was suitable for the purpose of decision in the presence of large population as mentioned by Poate \& Daplyn (1993), cited in Mari (2009). Therefore, the current study used a sample size of 70 off-season cucumber growers. Farmers were divided according to farm size in three groups which are small, medium and large. According to Hassan et al. (2005), a farmer having less than 12.5 acres was considered as small farmer; a farmer with greater than 12.5 acres and less than 25 acres was considered as medium; and a farmer having greater than 25 acres was considered as large. Software like Microsoft Excel, SPSS-15, DEAP-2.1 and Eviews 7 were used for empirical analysis.

\subsection{Efficiency Background}

A comparison between existing and maximum productivity of a firm is called as efficiency (Farrell, 1957). Maximum productivity of a firm was determined by using production frontier. Production frontier was developed by using two different techniques such as stochastic frontier analysis (SFA) and data envelopment analysis (DEA). The technique of linear programming was used in DEA model. The increasing difference among actual data and frontier explored the presence of increasing inefficiency of a firm (Javed, 2009). Coelli et al. (1998) mentioned both output and input oriented nature of DEA model but a farmer has more control on inputs. Therefore, input oriented DEA model was used in this study.

According to Javed (2009), technical efficiency is the achievement of maximum output by utilizing given input resources on the basis of production model. DEA model based on constant as well as variable return to scale was used for the estimation of technical efficiency. According to Coelli et al. (1998), constant returns to scale DEA model was feasible when all firms were working at an optimal scale otherwise it gives technical efficiency confounded by scale efficiency. Banker et al. (1984) incorporated convexity constraint in proposed variable returns to scale DEA model. DEA model based on constant and variable return to scale were used in this study.
2.2.1 Empirical Models

Present study calculated total technical and pure technical efficiency by using DEA model based on constant and variable return to scale, respectively. Total revenue $(\mathrm{Y})$ was considered as output variable in the calculation of efficiency scores. Land (X1), tractor (X2), seed (X3), fertilizer (X4), pesticide (X5), irrigation (X6), labour (X7), polythene sheet (X8) and mulch sheet (X9) were used as input variables in the analysis.

(a) DEA Model for technical efficiency estimation

Input oriented constant return to scale DEA model was applied for technical efficiency estimation as mentioned by Javed (2009) like:

$\min \theta, \lambda$,

subject to:

$-y i+Y \lambda \geq 0$

$\theta x i-X \lambda \geq 0$

$\lambda \geq 0$

Where:

$Y$ represents the output matrix for $\mathrm{N}$ off-season cucumber farmers.

$\theta$ represents the total technical efficiency.

$\lambda$ represents $\mathrm{Nx} 1$ constants.

$X$ represents input matrix for $\mathrm{N}$ off-season cucumber farmers.

$y i$ represents the total revenue (Rs.)

$x i$ represents the vector of inputs $\mathrm{x} 1 \mathrm{i}, \mathrm{x} 2 \mathrm{i}, \ldots \ldots \mathrm{x} 9 \mathrm{i}$

$X_{I i}$ represents the area under off-seasonal cucumber (acres)

$X_{2 i}$ represents the total tractor used (hours) in farm operations

$X_{3 i}$ represents the total quantity of seed $(\mathrm{kg})$

$x_{4 i}$ represents weight of NPK $(\mathrm{kg})$

$x_{5 i}$ represents the chemical applications (No.)

$X_{6 i}$ represents the total irrigation (hours)

$X_{7 i}$ represents the total labour man days required for all farm operations

$\mathrm{x}_{8 i}$ represents the polythene sheet weight $(\mathrm{kg})$

$\mathrm{X}_{9 i}$ represents the mulch sheet weight $(\mathrm{kg})$

(b) DEA Model for Pure Technical Efficiency Estimation

An input oriented variable return to scale DEA model was used by Coelli et al. (1998), cited in Javed (2009) for pure technical efficiency estimation. It is expressed as:

$\min \theta, \lambda$,

subject to

$-y i+Y \lambda \geq 0$
$\theta x i-X \lambda \geq 0$
$N 1^{\prime} \lambda=1$
$\lambda \geq 0$ 


656
Where:
$\quad \theta$ represents the pure technical efficiency for ith off-
season cucumber farmer.
$\mathrm{N} 1^{\prime} \lambda=1$ represents a convexity constraint to ensure
that an inefficient farmer was benchmarked against
same size farmers.

\section{(c) Scale Efficiency Estimation}

Scale efficiency was obtained by dividing total technical efficiency with pure technical efficiency and expressed as:

$\mathrm{SE}=\mathrm{TE}_{\mathrm{CRS}} / \mathrm{TE} \mathrm{VRS}_{\mathrm{V}}$

The firm was scale efficient or working at constant return to scale when it shows a value of 1 . A firm whose value of scale efficiency was less than 1 represents scale inefficiency. A firm's working either at increasing or decreasing return to scale causes scale inefficiency.

\section{(d) Economic Efficiency Estimation}

Cost minimization DEA model is considered as first step for the estimation of economic efficiency and it is simply a ratio between minimum to observed cost as mentioned by (Javed, 2009). Cost minimization DEA model was expressed as: $\min _{\lambda, x i}{ }^{E}$ wi $x i^{E}$

subject to

$-\mathrm{yi}+\mathrm{Y} \lambda \geq 0$

$\mathrm{xi}^{\mathrm{E}}-\mathrm{X} \lambda \geq 0$

$\mathrm{N} 1{ }^{\prime} \lambda=1$

$\lambda \geq 0$

Where:

wi represents input price vector w1i, w2 $\mathrm{i}$ ,........,w $9 \mathrm{i}$

$x i^{E}$ represents the vector of cost minimizing input quantities

$\mathrm{N}$ represents the total off-season cucumber farmers

$w_{l i}$ represents land rent in Rs.

$w_{2 i}$ represents total money spent on tractor use in Rs.

$w_{3 i}$ represents total cost of seed in Rs.

$w_{4 i}$ represents total cost of NPK in Rs.

$w_{5 i}$ represents total cost of pesticide in Rs.

$w_{6 i}$ represents total cost of irrigation in Rs.

$w_{7 i}$ represents total cost of labour in Rs.

$w_{8 i}$ represents total cost of polythene sheet in Rs.

$w_{9 i}$ represents total cost of mulch sheet in Rs.

Economic efficiency is simply a ratio between minimum cost and observed cost.

Economic Efficiency = minimum cost/observed cost $\mathrm{EE}=w i x i^{E} / w i x i$

(e) Estimation of Allocative Efficiency

Allocative efficiency is obtained by dividing economic efficiency with technical efficiency.

\section{$\mathrm{AE}=\mathrm{EE} / \mathrm{TE}$}

Allocative Efficiency = Economic Efficiency / Technical Efficiency

(f) Tobit Regression Model

Efficiency improvement studies also explored the causes of efficiency variations between different farmers (Ibrahim \& Omotesho, 2013). The score of inefficiency for each farmer was obtained by subtracting their efficiency score from 1 . The technical, allocative, and economic inefficiency score were separately regressed on selected variables. The range of efficiency score by using DEA model was from 0 to 1 . It shows that the dependent variable in the model was not normally distributed. Biasness in results becomes a hurdle for the use of ordinary least square technique (Javed, 2009). So, the current study used Tobit regression model proposed by Tobin (1958).

Socio-economic and farm related variables were education of farmer, family size, contact with extension agents, off-season cucumber growing experience and area, and distance of vegetable market. Tobit regression model used by Javed (2009) for the determinants of inefficiency was expressed as:

$E_{i=} E_{i}^{*}=\beta_{0}+\beta_{1} Z_{1 i}+\beta_{2} Z_{2 i}+\beta_{3} Z_{3 i}+\beta_{4} Z_{4 i}+\beta_{5} Z_{5 i}+\beta_{6} Z_{6 i}+\mu_{i}$

If $\mathrm{E}^{*}>0$

$\mathrm{E}=0 \quad$ if $\quad$ If $\mathrm{E}^{*} \leq 0$

Where

i represents ith farmer in the sample

Ei represents the technical, allocative, and economic inefficiency

Ei* represents the latent variable.

$Z_{1 \mathrm{i}}$ represents the education (years)

$\mathrm{Z}_{2 \mathrm{i}}$ represents the total family size (no.)

$\mathrm{Z}_{3 \mathrm{i}}$ represents the off-season cucumber experience (years)

$\mathrm{Z}_{4 \mathrm{i}}$ represents the contact with extension agents (no.)

$\mathrm{Z}_{5 \mathrm{i}}$ represents the area under off-season cucumber (acres)

$\mathrm{Z}_{6 \mathrm{i}}$ represents the vegetable market distance $(\mathrm{km})$ from ith farm

$\beta$ 's represents unknown parameters.

$\mu \mathrm{i}$ represents the error term.

\section{Results}

\subsection{Summary statistics}

Table 1 reveals the summary statistics of socio-economic variables. Average age of off-season cucumber growers was 40.81 years with minimum (15 years) and maximum ( 80 years). Mean value of education was 9 years. Average family size was 9.17 members with minimum (6) and maximum (24). 
Table 1 Summary statistics of socio-economic variables.

\begin{tabular}{|lccccc|}
\hline Variables & Unit & Mean & Maximum & Minimum & Standard Deviation \\
\hline Age & Year & 40.81 & 80 & 15 & 13.80 \\
\hline Education & Year & 9.00 & 18 & 0 & 4.97 \\
\hline Size of family & No. & 9.17 & 24 & 4 & 3.31 \\
\hline Off-season cucumber experience & Year & 6.85 & 20 & 1 & 4.52 \\
\hline Contact with extension agent & No. & 4.54 & 10 & 1 & 1.44 \\
\hline Off-season cucumber area & Acre & 4.61 & 40 & 0.5 & 5.79 \\
\hline Vegetable market distance & Km & 74.64 & 105 & 15 & 27.79 \\
\hline
\end{tabular}

Off-season cucumber growers had 6.85 years experience about this activity while some farmers were new entrants in this business. Extension services are also important for this business and off-season cucumber growers had 4.54 contacts with extension staff. On average, the cultivation area under cucumber in off-season was 4.61 acres. On average, the distance of vegetable market from cucumber farm was 74.64 $\mathrm{km}$.

Table 2 shows the summary statistics of variables incorporated in DEA model. It shows the mean value of a particular variable as well as their range. There exists variation in the use of input level because it depends on financial power of farmers and small farmers used fewer resources due to financial constraints. Credit availability was an alternative option but many farmers considered high interest as a hurdle to avail this opportunity. On average, per acre total output of off-season cucumber was 124.12 tonnes with minimum (26.78 tonnes) and maximum (220 tonnes). The wide range of output supported the concept of production inefficiency among the farmers. Per acre average revenue was Rs. 1,328,569.64 or Rs. 1.329 million (USD 12733.06). Total variable cost was Rs. $555,531.05$ and total cost was Rs. 671,935.96 calculated on per acre basis. On average, tunnel material cost was Rs. $61,205.14$ in this activity. Tunnel material cost do not includes the cost of long life tunnel material. The cost of long life tunnel material was a part of fixed cost in the form of depreciation. A farmer paid Rs. $29,270.83$ in the form of land rent calculated for seven months in off-season cucumber production. Tractor cost was Rs. 14,391.07 on average. On average, a farmer allocated Rs. $55,653.93$ as seed cost. Average expenditure on fertilizer was Rs. 100,559.64. Chemical cost in off-season cucumber production was Rs. 38,607.14 per acre. Cultivation of cucumber is a water intensive activity and a farmer spends Rs. 15,528.82 on irrigation. Labor was used in various farm practices. On average, the share of labour in total variable cost was Rs. 102,711.07 with minimum (Rs. 32,000.00) and maximum (Rs. 198,750.00).

Table 2 Summary statistics of variables used in DEA model.

\begin{tabular}{|c|c|c|c|c|c|}
\hline Variables & Unit & Mean & Minimum & Maximum & Standard Deviation \\
\hline Yield & Kg/acre & 124123.21 & 26775.00 & 220000.00 & 31955.61 \\
\hline Revenue & Rs./acre & 1328569.64 & 630000.00 & 2200000.00 & 294432.92 \\
\hline Variable cost $^{1}$ & Rs./acre & 555531.05 & 183205.00 & 825570.00 & 123328.34 \\
\hline Total $\operatorname{cost}^{2}$ & Rs./acre & 671935.96 & 242988.05 & 975329.37 & 147565.27 \\
\hline Tunnel material $\operatorname{cost}^{3}$ & Rs. & 61205.14 & 18140.00 & 103950.00 & 19594.85 \\
\hline Land rent & Rs./acre & 29270.83 & 17500.00 & 40833.33 & 6073.16 \\
\hline Tractor use cost & Rs./acre & 14391.07 & 7250.00 & 25500.00 & 3077.37 \\
\hline Seed cost & Rs./acre & 55653.93 & 25000.00 & 162000.00 & 17799.66 \\
\hline NPK cost & Rs./acre & 100559.64 & 13800.00 & 251375.00 & 45270.00 \\
\hline Chemical cost & Rs./acre & 38607.14 & 5000.00 & 65000.00 & 11880.72 \\
\hline Irrigation cost & Rs./acre & 15528.82 & 4180.00 & 68000.00 & 9485.92 \\
\hline Labor cost & Rs./acre & 102711.07 & 32000.00 & 198750.00 & 26314.77 \\
\hline
\end{tabular}

On per acre basis -

${ }^{I}$ Variable cost consists of tunnel preparation cost, land preparation cost, seed cost, pesticide cost, irrigation cost, fertilization cost, picking cost and marketing cost; ${ }^{2}$ Fixed cost includes depreciation, interest on initial investment, interest on variable cost, administration charges, rent of land and water charges by Govt. (abyana); ${ }^{3}$ Tunnel material cost includes cost of string, nut bolt, polythene sheet, mulch sheet, labour charges 
Table 3 Frequency distribution of efficiencies.

\begin{tabular}{|c|c|c|c|c|c|c|}
\hline \multirow[t]{2}{*}{ Efficiency range } & \multicolumn{2}{|c|}{ Technical efficiency } & \multicolumn{2}{|c|}{ Allocative efficiency } & \multicolumn{2}{|c|}{ Economic efficiency } \\
\hline & $\mathrm{N}$ & $\%$ & $\mathrm{~N}$ & $\%$ & $\mathrm{~N}$ & $\%$ \\
\hline $0.01-0.30$ & 0 & 0 & 33 & 47.15 & 35 & 50 \\
\hline $0.31-0.40$ & 0 & 0 & 4 & 5.71 & 8 & 11.43 \\
\hline $0.41-0.50$ & 0 & 0 & 11 & 15.71 & 8 & 11.43 \\
\hline $0.51-0.60$ & 0 & 0 & 4 & 5.71 & 8 & 11.43 \\
\hline $0.61-0.70$ & 5 & 7.14 & 9 & 12.86 & 5 & 7.14 \\
\hline $0.71-0.80$ & 21 & 30 & 5 & 7.14 & 2 & 2.86 \\
\hline $0.81-0.90$ & 14 & 20 & 3 & 4.29 & 3 & 4.29 \\
\hline $0.91-1.00$ & 30 & 42.86 & 1 & 1.43 & 1 & 1.43 \\
\hline Total & 70 & 100 & 70 & 100 & 70 & 100 \\
\hline Mean & \multicolumn{2}{|c|}{0.874} & \multicolumn{2}{|c|}{0.420} & \multicolumn{2}{|c|}{0.372} \\
\hline Maximum & \multicolumn{2}{|c|}{1} & \multicolumn{2}{|c|}{1} & \multicolumn{2}{|c|}{1} \\
\hline Minimum & \multicolumn{2}{|c|}{0.607} & \multicolumn{2}{|c|}{0.137} & \multicolumn{2}{|c|}{0.099} \\
\hline
\end{tabular}

\subsection{Efficiency score estimation}

Table 3 reveals that the mean total technical efficiency in the production of off-season cucumber was $87.4 \%$ with minimum $(60.7 \%)$ and maximum (100\%). It depicts the possibility of $12.6 \%$ reduction in inputs for working at technical efficient level while output and technology remains unchanged. Results showed that $42.86 \%$ off-season cucumber growers had more than $90 \%$ value of technical efficiency and $57.14 \%$ remaining falls between $60 \%$ and $90 \%$. Average value of allocative efficiency was $42 \%$ with lowest $(13.7 \%)$ and highest $(100 \%)$. It depicts the possibility of $58.0 \%$ reduction in total cost for an allocatively efficient farmer keeping the level of output and technology constant. Score of allocative efficiency was more than $70 \%$ for only $12.86 \%$ farmers. Average pure technical efficiency was $96.4 \%$ with lowest (78.3\%) and highest (100\%). It is more due to the absence of production scale. Average scale efficiency was $90.4 \%$ with lowest $(62.7 \%)$ and highest (100\%). Economic efficiency was $37.2 \%$ on average with minimum $(9.9 \%)$ and maximum $(100 \%)$.

Table 4 explores the impact of farm size efficiency scores. All production efficiency scores were found for small, medium and large off-season cucumber farmers. The mean of total technical efficiency was $96.7 \%$ for medium farmers followed by large (95.0\%) and small $(92.1 \%)$ farmers. The average allocative efficiency was higher for small farmers $(49.0 \%)$ followed by medium $(48.0 \%)$ and large $(43.1 \%)$ farmers. Economic efficiency was more for medium farmers and it was $46.5 \%$ on average while its value was $45.7 \%$ and $40.8 \%$ for small and large farmers, respectively. Small farmers were more in Pakistan and their prosperity was also important for the uplift of Pakistani society (Adil et al., 2004).

\subsection{Inefficiency determinants}

\subsubsection{Education}

Education was included to test the hypothesis that a farmer with more schooling is more efficient in off-season cucumber production. The results revealed a negative and significant education coefficient for economic and allocative inefficiency. Therefore, it confirmed the hypothesis and showed a decrease in allocative and economic inefficiency with increase in education.

\subsubsection{Family Size}

Family size was included to test the hypothesis that a farmer with increasing size of family had high value of inefficiency score. There exists a significant and positive coefficient for the size of family in off-season cucumber production for all production inefficiencies. So, it confirmed the direct relationship of inefficiency score with family size. Generally a farmer spends more financial resource in case of large family and has fewer resources to invest in a business that involve new technology. Off-season cucumber cultivation is profitable but requires higher initial investment.

Table 4 Estimation of production efficiencies with respect to farm size.

\begin{tabular}{|lccccc|}
\hline \multirow{2}{*}{ Farm Size } & \multicolumn{5}{c|}{ Efficiency estimates } \\
\cline { 2 - 6 } & $\mathrm{TE}_{(\mathrm{CRS})}$ & $\mathrm{TE}_{(\mathrm{VRS})}$ & $\mathrm{SE}$ & $\mathrm{AE}$ & $\mathrm{EE}$ \\
\hline Small & 0.921 & 0.995 & 0.925 & 0.490 & 0.457 \\
\hline Medium & 0.967 & 0.994 & 0.972 & 0.480 & 0.465 \\
\hline Large & 0.950 & 0.982 & 0.968 & 0.431 & 0.408 \\
\hline
\end{tabular}


Table 5 Determinants of inefficiency.

\begin{tabular}{|c|c|c|c|c|c|c|c|}
\hline \multirow[t]{2}{*}{ Variables } & \multirow[b]{2}{*}{ Unit } & \multicolumn{2}{|c|}{ Technical inefficiency } & \multicolumn{2}{|c|}{ Allocative inefficiency } & \multicolumn{2}{|c|}{ Economic inefficiency } \\
\hline & & $\beta$ & Sig. & $\beta$ & Sig. & $\beta$ & Sig. \\
\hline Education & year & 0.007 & 0.381 & -0.009 & 0.015 & -0.007 & 0.002 \\
\hline Size of family & no. & 0.081 & 0.000 & 0.094 & 0.000 & 0.072 & 0.000 \\
\hline Off-season cucumber experience & year & -0.050 & 0.001 & -0.022 & 0.000 & -0.002 & 0.522 \\
\hline Extension agent contacts & no. & -0.171 & 0.000 & -0.008 & 0.074 & -0.014 & 0.000 \\
\hline Off-season cucumber area & acre & 0.037 & 0.019 & 0.022 & 0.000 & 0.001 & 0.854 \\
\hline Vegetable market distance & $\mathrm{km}$ & 0.010 & 0.000 & -0.001 & 0.163 & 0.000 & 0.129 \\
\hline
\end{tabular}

\subsubsection{Off-season cucumber experience}

Experience in off-season cucumber cultivation was included to test the hypothesis that the inefficiency decreases with increase in experience. The coefficient of experience was significant and negative for technical as well as allocative inefficiency. It revealed that the decrease in the level of inefficiency was associated with the increase in the value of off-season cucumber growing experience.

\subsubsection{Contact with extension agent}

Extension services are important for a new technique and it was included to test the hypothesis that there is a negative impact on production inefficiency in the presence of extension services. The coefficient of contacts with extension agents was significant and negative for all kind of production inefficiency. It showed that the value of inefficiency decreases when a farmers increases the contact with extension staff.

\subsubsection{Off-season cucumber area}

The coefficient of off-season cucumber area was positive and significant for allocative and technical inefficiency. It showed an increase in the value of inefficiency due to more area under control. Generally small farmers were recognized as more efficient because they utilize the scarce resources more efficiently.

\subsubsection{Distance of vegetable market}

Distance between vegetable market and vegetable farm was included to test the hypothesis that a distant farm had more value of inefficiency. The coefficient of distance from vegetable market was significant and positive for technical inefficiency. A distant vegetable farm bears more labour cost and transportation cost.

\section{Discussion and Conclusions}

The present research explored the technical, allocative and economic efficiency in cucumber production in off-season with the help of primary data collected from 70 respondents in Punjab, Pakistan. Data Envelopment Analysis showed a higher mean value for technical efficiency $(87.4 \%)$ followed by allocative $(42.0 \%)$ and economic $(37.2 \%)$ efficiency. It explored the possibility of $12.6 \%$ reduction in inputs and $58.0 \%$ reduction in production cost for a technical and allocative efficient farmer while output and technology remains unchanged. The mean value of technical efficiency was $77 \%$ in cucumber production as found by Shrestha et al. (2014). Tobit regression was applied to explore the sources of technical, allocative and economic inefficiency. Results showed that the education, experience of cucumber cultivation in off-season, contacts with extension agents had significant and negative effect on production inefficiency. The negative effect of education on inefficiency was also explored by Bozoglu \& Ceyhan (2007); Ogunniyi \& Oladejo (2011); Shaheen et al. (2011); Khan (2012); Adenuga et al. (2013); Khan \& Ali (2013) and Shrestha et al. (2014). The effect of family size on production inefficiency was matched with Bozoglu \& Ceyhan (2007).

The impact of extension service was in line with the findings of Bozoglu \& Ceyhan (2007), Khan (2012), Khan \& Ali (2013) and Shrestha et al. (2014). The impact of family size, area under off-season cucumber and vegetable market distance was significant and positive on the score of technical, allocative and economic inefficiency. Result confirmed a significant potential for the improvement of technical, allocative and economic efficiency in off-season cucumber production.

Government should improve the technical education of farmers for the decrease in inefficiency score. Extension department should improve their contact with farmers and create awareness about this profitable business. Government should control the prices of various inputs like fertilizers, hybrid seed, electricity and chemicals. Government should also improve the quality of inputs like seed, sprays and fertilizers. High Initial investment on tunnel material is a problem for small farmers. Government should provide subsidy to small farmers in the construction of tunnel structure.

\section{Conflict of interest}

Authors would hereby like to declare that there is no conflict of interests that could possibly arise. 


\section{References}

Adenuga AH, Lawal AM, Rotimi OA (2013) Economics and technical efficiency of dry season tomato production. Agris online Papers in Economics and Informatics in selected areas in Kwara state, Nigeria 5: 11-19.

Adil SA, Badar H, Sher T (2004) Factors affecting gross income of small farmers in district Jhang-Pakistan. Pakistan Journal of Life and Social Sciences 2: 153-155.

Akter S, Islam MS, Rahman MS (2011) An economic analysis of winter vegetables production in some selected areas of Narsingdi district. Journal of Bangladesh Agricultural University 9: 241-246.

Alboghdady MAA, Shata MA (2014) Stochastic frontier analysis of cucumber production under different cultivation systems in Ismailia Governorate, Egypt. Journal of Agricultural Economics and Social Sciences, Mansoura University 5: 1063-1073.

Banker RD, Charnes A, Cooper WW (1984) Some models for estimating technical efficiency and scale inefficiencies in data envelopment analysis. Management Science 30: 1078-1092.

Bozoglu M, Ceyhan V (2007) Measuring the technical efficiency and exploring the inefficiency determinants of vegetable farms in Samsun province, Turkey. Agricultural Systems 94: 649-656.

Coelli T, Rao DSP, Battese GE (1998) An introduction to efficiency and productivity analysis. Kluwer Academic Publishers, Boston.

FAO (2016) Food and Agriculture Organization of the United Nations. available on http://faostat3.fao.org accessed on May 20, 2016.

Farrell M (1957) The measurement of productivity efficiency. Journal of Royal Statistical Society, Series A 120: 253-290.

Government of Pakistan (2013) Pre-feasibility study (offseason vegetable farming-high tunnel). Small and Medium Enterprises Development Authority, Ministry of Industries \& Production, Lahore.

Government of Pakistan (2014) Fruit, vegetables and condiments statistics of Pakistan. Ministry of National Food Security \& Research, Islamabad.

Government of Pakistan (2015) Economic survey of Pakistan. Ministry of Finance, Islamabad.

Government of Pakistan (2016a) Economic survey of Pakistan. Ministry of Finance, Islamabad.

Government of Pakistan (2016b) External trade statistics. Statistical Bureau of Pakistan, Islamabad.
Hassan S, Tabasam N, Iqbal J (2005) An economic analysis of wheat farming in the mixed farming zone of Punjab province, Pakistan. Journal of Agriculture and Social Sciences 1: 167171.

Ibrahim HY, Omotesho OA (2013) Determinant of technical efficiency in vegetable production under Fadama in northern guinea savannah, Nigeria. Journal of Agricultural Technology 9: 1367-1379.

Iqbal Q, Amjad M, Asi MR, Ali MA, Ahmad R (2009) Vegetative and reproductive evaluation of hot peppers under different plastic mulches in poly/plastic tunnel. Pakistan Journal of Agricultural Sciences 46: 113-118.

Javed MI (2009) Efficiency analysis of cotton-wheat and ricewheat systems in Punjab, Pakistan. Ph.D. Thesis submitted to Faculty of Agricultural Economics and Rural Sociology, University of Agriculture, Faisalabad.

Khan H (2012) Measurement of technical, allocative and economic efficiency of tomato farms in Northern Pakistan. Journal of Agricultural Science and Technology B2: 10801090.

Khan H, Ali F (2013) Measurement of productive efficiency of tomato growers in Peshawar, Pakistan. Czech Agricultural Economics 59: 381-388.

Khan REA, Ghafar S (2013) Technical efficiency of tomato production: A case study of district Peshawar (Pakistan). World Applied Sciences Journal 28: 1389-1392.

Khan Z, Shah AH, Gul R, Majid A, Khan U, Ahmad H (2015) Morpho-agronomic characterization of cucumber germplasm for yield and yield associated traits. International Journal of Agronomy and Agricultural Research 6: 1-6.

Mari FM (2009) Structure and efficiency analysis of vegetable production and marketing in Sindh, Pakistan. Ph.D Thesis submitted to Department of Agricultural Economics, Sindh Agriculture University, Tando Jam, Pakistan.

Maurya GP, Pal V, Singh GP, Meena LK (2015) An economic analysis of cucumber cultivation in Sultanpur District of Uttar Pradesh (India). International Journal of Agricultural Science and Research 5: 23-28.

Ogunniyi LT, Oladejo JA (2011) Technical efficiency of tomato production in Oyo state Nigeria. Agricultural Science Research Journal 1: 84-91.

Poate CD, Daplyn PF (1993) Data for agrarian development. Cambridge University Press.

Sanjeev K, Patel NB, Saravaiya SN, Desai KD (2015) Economic viability of cucumber cultivation under NVPH. 
African Journal of Agricultural Research 10: 742-747. DOI: 10.5897/AJAR2014.9407

Shaheen S, Anwar S, Hussain Z (2011) Technical efficiency of off-season cauliflower production in Punjab. Journal of Agricultural Research 49: 391-406.
Shrestha RB, Huang WC, Ghimire R (2014) Production efficiency of smallholder vegetable farms in Ilam district, Eastern Hill, Nepal. American-Eurasian Journal of Agricultural and Environmental Sciences 14: 150-154.

Tobin J (1958) Estimation of relationships for limited dependent variables. Econometrica 26: 24-36. 